\title{
HETERONORMATIVE HIGHER EDUCATION: CHALLENGING THIS STATUS QUO THROUGH LGBTIQ AWARENESS-RAISING
}

\author{
G. Matthyse
}

Gender Equity Unit

University of the Western Cape

Bellville, South Africa

e-mail: gmatthyse@uwc.ac.za

\section{ABSTRACT}

This article focus on the challenges homophobia and transphobia pose to LGBTIQ students at the University of the Western Cape (UWC), a historically black peri-urban university located on the margins of Cape Town. Both the geographical location as well as the internal environment of the university give rise to various challenges for LGBTIQ identifying, and particularly gender nonconforming, students around their sexual freedom and self-affirmation. In transcending the vacuum between the challenges faced by these students and the existing human rights discourse on non-normative sexual orientations and gender identities, the Gender Equity Unit, through its student-driven LGBTIQ programme LoudEnuf, its support staff and in collaboration with the student structure GaylaUWC has been educating and sensitising the campus community through its intersectional awareness-raising initiatives. This article focuses on the effectiveness of awareness-raising in creating a welcoming, comfortable, liberating and safe campus for LGBTIQ students to access comprehensive quality education.

Keywords: South Africa, university, LGBTIQ, support staff, awareness

\section{INTRODUCTION}

Historically, lesbian, gay, bisexual, transgender, intersex, queer/questioning (LGBTIQ) identifying people have been subjected to legal discrimination coupled with social marginalisation in South Africa (Gevisser and Cameron 1995; Arndt and De Bruin 2006, 16). The legal framework that was operational prior to 1994 criminalised non-normative sexual identities and repressed non-normative gender identities and expressions. Today, a very progressive post-1994 Constitution and legal framework affirm the rights of LGBTIQ people. However, peoples' attitudes in schools and social systems are yet to improve (Van Vollenhoven and Els 2013, 281). A study found that 76 per cent of tertiary educated people were homophobic and by extension transphobic (Equality Report 2012).

The University of the Western Cape (UWC), a peri-urban university located on the margins of Cape Town, in the Western Cape province of South Africa, has its roots firmly set 
in the dismantling of apartheid and 'contributing to helping the historically marginalised participate fully in the life of the nation' (UWC Mission Statement 2007). Hames (Director of the Gender Equity Unit - UWC), correctly argues that based on the university's comprehensive focus on social justice, steered predominantly by its staff and students, that same-sex orientation is included in the scope of people who are marginalised (Hames, 2007: 59). With the promulgation of the Alteration of Sex Description and Sex Status Act (2003), the concept 'gender identity' gained more prominence. Transgender people experience marginalisation differently than gay, lesbian and bisexual people. Gender identity, in addition to sexual orientation, must thus be included within the institution's comprehensive focus on social justice.

This article addresses the ways in which stigma, prejudice and discrimination against LGBTIQ students is manifested in the higher educational context (both inside and outside the classroom) and how the Gender Equity Unit at UWC mitigates the impact through awarenessraising initiatives.

\section{METHODOLOGY}

This article is predominantly an autoethnographic study, where I, the researcher, are afforded opportunities to explore my past and present experiences initially as a LGBTIQ identifying student, student leader of an LGBTIQ student organisation, and subsequently as a university administrative staff member working with LGBTIQ identifying students (Butler 2009, 295). Although the focus on self-narrative is a good way to explore and understand self and others, acknowledgement is given as to the limitations it poses, in not being sufficient to gain an understanding of self and others (Chang 2008; Butler 2009, 295). This autoethnographic study is analytical, as I, make myself visible in the text and position my experience in the research in relation and addition to the experiences of other LGBTIQ identifying students in order to obtain an understanding of a broader campus social phenomenon (Chang 2008, 375; Butler 2009, 296). I fully understand that this autobiographical stance lends itself to subjectivity but find it a necessary method to write about a topic not often covered in current or past South African academic research.

This approach allows me to position my own experience in relation to others and incorporate their experiences into this article. I am also caught in the binarism of being both insider and outsider. Chmielewski and Yost (2013) position 'insider' research as an approach to qualitative research where investigation regarding a particular phenomenon is undertaken in a manner through which the investigator studies hirself, people like hir, hir's family, as well as 
community (Wilkinson and Kitzinger 2013, 251). Although insider status may potentially influence the research process (Hockey 1993) it challenges the claim that only sensitised outsider researchers can discover the 'objective’ reality(ies) of other cultures and groups (Lewis 1973; Wilkinson and Kitzinger 2013, 251). The advantage of being an insider is that one has a deeper understanding of the history of the institution, the institutional culture and the interplay between people and stakeholders (Hanson 2013, 391).

This reflexive article is premised on my personal experiences in different roles and what Wilkinson and Kitzinger (2013) terms '[my] priori intimate knowledge' of the queer communities and its members at UWC and elsewhere. Through the different roles I fulfilled over time, I am aware of the shifting status of insider/outsider from moment to moment (Kitzinger and Kitzinger 2012; Wilkinson and Kitzinger 2013, 252). As a queer identifying student and leader of GaylaUWC I am automatically an insider. However, as a full-time staff member and researcher of the University, although queer and still a student, I occupy a space at a relative distance and power to the lived realities of the queer students I work with. Hence, I would be positioned what Grant (2007) describes as a 'central' outsider (Hanson 2013, 389). Consequently, I predominantly draw on the 'maximising' approach in 'insider' research that largely focuses on my own personal experiences but which I connect to the prevailing heteronormative institutional culture (Ellis and Bochner 2000, 739; Wilkinson and Kitzinger 2013, 253). I am acutely aware of the danger in silencing other queer experiences on campus by over-representing and over-privileging my experiences (Wilkinson and Kitzinger 2013, 254). In mitigating the challenge that my voice is positioned as the dominant by negating the plurality of queer experiences on campus, this article also draws on the 'insider' research approaches of 'utilising' and 'incorporating'. I draw on my experience strategically to connect with student activists in the field. In this way I am able to incorporate other queer experiences alongside my own.

In support of my autobiographical approach I use anecdotal evidence as provided by students and the media. This article does not focus on an in-depth analysis of the narratives of the participants. It however highlights the incidences and their relations to broader social, cultural and political imperatives for LGBTIQ students. Incidences referred to that are not necessarily formally recorded, but of which I have personal knowledge through my interactions, are referred to in an anecdotal manner that seeks to protect identity and minimise the risk of students being identifiable. 


\section{LEGISLATIVE AND POLICY BLUEPRINT FOR TRANSFORMATION IN HIGHER EDUCATION}

Through the liberal democracy and its constitutional mechanisms South Africa is seeking to redress discrimination facing marginalised groups, including people marginalised on account of their sexual orientation and gender identity (Constitution of South Africa 1996, section 9; Alteration of Sex Description and Sex Status Act 49 of 2003; Promotion of Equality and Prevention of Unfair Discrimination Act 4 of 2000, sections 2, 10, 11, 12 and 17).

In the 1997 White Paper on Higher Education sexual orientation was included as one of the focus areas for building a safe and secure campus environment that would discourage harassment and hostile behaviour towards LGBTIQ people (White Paper 3 on the Transformation of Higher Education 1997, 3.42). However, subsequently, unlike the 1997 White Paper on Higher Education, the current White Paper for Post-school Education and Training (2014) is silent about the homophobia and transphobia which plagues South Africa and its institutions of higher learning. Msibi $(2013,65)$ argues that the transformational agenda in higher education tended to focus more on race and sex to the detriment of other forms of discrimination. Hence, Hames $(2007,57)$ questions whether the initial inclusion of sexual orientation was but a mere 'token'.

The White Paper for Post-school Education and Training $(2014,1)$ acknowledges that irrespective of the advances made by institutions since the advent of democracy it still replicates the divisions of apartheid. In as much as the article expressly acknowledges the racism that black students at formerly whites-only institutions are subjected to, the sexism that women are victims to in patriarchal systems, the plights of poor students, the structural challenges of differently-abled students and adult-education; so too the argument can be made that LGBTIQ students are subjected to homophobia and transphobia that is rooted in heterosexist, cisnormative and heteronormative institutional cultures (White Paper on Post-school Education and Training 2014, 1). Yet, the White Paper is essentially silent on issues of sexuality, sexual orientation and gender identity.

In 2014 the Ministry of Higher Education and Training presented a Draft Social Inclusion Policy Framework for Public Post-school Education and Training Institutions that seeks to respond to the discrimination, social exclusion and marginalisation that (black)women, LGBTIQ people, persons with disabilities and persons from rural and disadvantaged backgrounds face within institutions of higher learning (Government Gazette General Notice 68, 2014). It is encouraging to note that the Draft Policy expressly acknowledge the outburst of homophobic (and transphobic) violence that plagues South African society. Should the Draft 
Policy be adopted it will progressively task institutions of higher learning with the responsibility of ensuring that people with non-normative sexual orientations and gender identities are able to express themselves without fear of intimidation or harassment.

Despite formal laws and policies, the challenge remains how to conscientise people, both LGBTIQ identifying and heterosexual, on the rights accruing to LGBTIQ people. How could these laws and policies be implemented to positively and radically transform the institutional cultures of institutions of higher learning in a way that is conducive to the physical, emotional and psychological wellbeing and intellectual growth of LGBTIQ students? Muller (2000) argues that institutions can either actively and fully implement state-initiated policies, do so reluctantly thus making them ineffective, or implement them passively with mere toleration of the 'Other'. Hence, in order to ensure that transformation occurs, progressive groups and stakeholders at our institutions of higher learning must take ownership of the role we play in setting up the human rights and social justice agenda and addressing the challenges faced by LGBTIQ, and other marginalised students, both socially and academically, in accessing quality higher education.

\section{INCIDENCES OF HOMOPHOBIA AND TRANSPHOBIA AT THE UNIVERSITY OF THE WESTERN CAPE}

\section{Safety and security}

As part of my own experience of stigma and phobia I am relating the following anecdote:

In October 2012, the University of the Western Cape (UWC) made headline news when gender non-conforming ${ }^{1}$ students were brutally attacked on residence (Davids 2012, 2). I was one of the students in this group. On our way to one of the residences we were subjected to hate speech and were called derogatory names such as 'moffies', 'faggots' and 'izzistabane' until a verbal confrontation ensued which ended violently. As the attack continued, security personnel stood by idly watching from the security booth and later claiming that they were too scared to intervene and that they were waiting for back-up. Subsequent to the attack, when the South African Police Services (SAPS) arrived on the scene, one of the police officers grinned and chuckled when I tried to explain what had happened. Later in response to questions posed by the media, the university spokesperson defensively stated that we were drunk, unruly and insulting (Mail \& Guardian online 2012).

In theorising the above incident - I refer to Reid and Dirsuweit (2002, 99) who argue that citizenship comprises of one's ability to move, use and express identity freely and that violence is an extreme action aimed at curtailing such rights (Constitution of South Africa 1996, sections 10, 12, 14, and 18). Linking national and academic citizenship, Garvey and Rankin (2015, 378) 
reason that LGBTIQ students are inhibited from coming out due to hostile campus environments (Rankin, Weber, Blumenfeld and Frazer 2010). For trans-spectrum students (including gender non-conforming students), the experience can be particularly hostile based on the manner in which they overtly express themselves through name-changing, use of pronouns and body modification (Garvey and Rankin 2015, 377).

Although limited research exists, the current trend indicates that trans-spectrum students are more likely to experience harassment than cisgender students (Garvey and Rankin 2015, 382). LGBTIQ people underreport hate-crimes to police as they fear unsympathetic and hostile responses (Herek and Berrill 1992). De Vos, in his blog, Constitutionally Speaking, refer to the response of UWC's spokesperson and situates it within the context of 'blaming the victim' (De Vos 2012). He argues that the act of blaming those on the receiving end of blatant discrimination and prejudice as opposed to condemning such behaviour is a 'sickness' that has seemingly infected university actors.

\section{Access control and toilet usage}

Another incident, that has also received much public and media attention, is that of non-existent toilet-usage policies for gender non-conforming people.

As a group of male-born individuals we decided to dress up in clothing typically associated with the female sex. We went to a recreational spot on campus which we frequented regularly. Upon going to the toilet designated for males we were harassed. My friend who was guarding the toiletdoor for me was pushed to the floor and the toilet-door was kicked in. Having been publicly humiliated I rushed over to the toilet designated for females. I asked a friend if I could use one of the cubicles. Upon being informed that I was in the female toilet, a male security guard entered the facility in order to get me out of a space I supposedly did not belong in. A few females barricaded the door of the toilet that I was in denying him access to use force to get me out. Upon continuously being harassed to come out, I opened the door. The security guard pushed me to the side and up against the wall. In this way intimidating me to never again use the female toilet. Consequently, I left the establishment with my friends and was told to be dressed appropriately the next time we entered.

Consistently, gender non-conforming students are being alienated from facilities such as toilets and recreational establishments which many heteronormative, cisnormative and/or homonormative people take for granted. Cavanagh (2010) argues that the challenges experienced by people falling outside the binary organisation in toilet usage and practice is a consequence of bodies disrupting what society deems its successful organisation of hygienic public spaces (Lorber 2012, 598). Bathroom spaces reflect cultural beliefs about privacy and sexuality (Gershenson 2010, 192) and is a disciplinary space filled with political meanings that highlights a cultural (institutional and university) strategy that seeks to preserve heteronormativity and cisnormativity (Reid and Dirsuweit 2002, 100; Foucault 1988; Butler 
1990; Gershenson 2010, 193). Women's and men's bathrooms are thus premised on heterosexual and cisgender assumption and ignores same sex sexuality and diverse gender identities and expressions (Gershenson 2010, 193).

Public spaces are thus coded to be heterosexual and cisgender. Toilet spaces, especially public toilets, are also political spaces for other groups such as feminists in opposition to 'degendering' toilets and who advocate for the existence of segregated facilities (Jeffreys 2014, 42). According to Valentine (1993, 396), although people state that they do not object to nonnormative sexualities and expressions, many feel that these should not find expression in public. With toilets being politically and socially contested spaces, how do we address this matter within our institutions in a way that will allow all to feel dignified and safe without letting gender non-conforming people slip through the cracks?

\section{Prejudice and privilege}

The following anecdotes provide evidence as to the harassment LGBTIQ students are subjected to based on their sexual orientation and gender identity. In relation to freedom of movement on campus:

Moving around on campus as someone defying gender norms set by society can also be very daunting. A level of entitlement exist whereby heterosexual and cisgender students appear to feel justified when humiliating LGBTIQ students through derogative name-calling. The silent judgemental stares when walking by a group of students and the subsequent talks and laughs does not faze one gender non-conforming student.

With regards to campus housing:

When it comes to residence, gender non-conforming students once more bear the brunt of institutional oppression. This is especially the case where students are housed in gender segregated halls and where two students of the same birth-sex, are assumed to be heterosexual, and put into one room. Some time ago, a House Committee member of one of the residences on campus approached the Gender Equity Unit to address a matter where an LGBTIQ identifying student complained about being continuously victimised by a heterosexual identifying room-mate. The room-mate would play heterosexual pornographic videos loudly in the room and directly questioned the student's sexuality. The heterosexual identifying student would also engage in heterosexual sexual intercourse in the student's presence.

Research reveals that one out of six pupils in school, identifying as gender non-conforming, is likely to leave due to harassment (Garvey and Rankin 2015, 384). According to the South African Human Rights Commission (Equality Report 2012, 55), ‘LGBTIQ people are exposed to the same challenges as most South African youth but continuing homophobia [and transphobia] at home, school and in society makes it worse. LGBTIQ people are 
disproportionately prone to mental illness, suicide, and alcohol and drug abuse than their hererosexual and cisgender counterparts due to the trauma they experience based on their sexual orientation and/or gender identity' (Equality Report 2012, 55). An institutional culture of homophobia and transphobia creates undue challenges for LGBTIQ students to what Akoojee and Nkomo (2007, 390) calls 'access to success' in higher education as opposed to mere 'access with participation' as a transformational imperative. Universities should be places that are affirming and supportive where all students are able to explore their sexual and gender identities as this is likely to yield positive academic and development outcomes (Garvey and Rankin 2015, 383).

\section{Adverse classroom experiences}

Campus classrooms are breeding grounds for homophobia and transphobia. Rankin (2003) argues that cisgender-centric classroom environments damages trans-inclusivity and affirmation (Garvey and Rankin 2015, 383), especially when students feel invisible and/or silenced (Lopez and Chims 1993; Renn 2000). The following anecdote gives evidence of the classroom homophobia:

Whilst sitting in my undergraduate class, a student asked a question. The seemingly progressive lecturer addressed the student as 'Mr' and subsequently continued to apologise suggesting that he may have used the incorrect pronoun. Students burst into laughter on account of the lecturer's response.

Lovaas, Baroudi and Collins (2002) discuss the unique challenges that both teachers and students are faced with when having to engage with sexuality and gender as a marked focus of the curriculum as well as having to address these in unrelated classroom discussions. If not adequately prepared on how to engage these matters in the context in which they arise, an instructor runs the risk of objectifying and humiliating certain students on account of their actual or perceived sexuality and/or gender identity (Lopez and Chims 1993, 98). In a class that has not been sensitised about gender non-conformity or being LGBTIQ identifying, gender nonconforming and LGBTIQ students are open targets to be ridiculed and victimised.

\section{INSTITUTIONAL RESPONSE: STIMULATING CRITICAL CONSCIOUSNESS THROUGH AWARENESS-RAISING AND ADVOCACY}

Gherhardi (1995) asserts that organisational culture is not something that is overtly noticeable by its people. This means, that institutional cultures can in actual fact guide the behaviour and beliefs of people which in turn influences the way the institution functions, if people are not 
aware of this (Shackleton 2007, 23). A critical aspect of affecting transformation is the adoption and implementation of appropriate intervention, public education, awareness-raising and advocacy programmes in order to stimulate critical consciousness within the institution (Butler, Alpaslan, Strüumpher and Astbury 2003). Since 2006, the Gender Equity Unit has proactively been pioneering the struggle against institutional homophobia and transphobia through studentdriven awareness-raising programmes.

In response to the incidences around safety and security on campus, a multi-stakeholders meeting was called by the Gender Equity Unit. Renn (2000) correctly asserts that campus-based units and centres that focuses on creating safe and inclusive spaces for LGBTIQ identifying students are critical in healthy sexual and gender identity formation (Garvey and Rankin 2015, 379). Various campus stakeholders involved in student development attended the meeting. The meetings discussed applicable institutional remedies to address homophobia and transphobia on campus. It unanimously concluded that stakeholders would be provided with regular and relevant workshops focussed on LGBTIQ students’ health, safety and overall wellbeing. This platform strengthened existing, and formed new strategic alliances and partnerships within the university, which is critical to challenging homophobia and transphobia through awarenessraising. In a media report, the Director for Student Support Services stated that '[We] are painfully aware of the miles we still have to walk to achieve equality and freedom for LGBTIs' (Glam 2014, 24). This certainly brings about some encouragement that the institutional landscape and actors, not necessarily institutional culture, might be changing.

The Gender Equity Unit provided guidance to the student structure GaylaUWC on how to engage around matters of sexualities and gender identities during a meeting set up by Student Support Services, the owners of a recreational establishment and members of GaylaUWC. The resolution reached provided that students may use toilets in the establishment in conformity with their gender expression. The problem with this agreement was that it provided that the names of gender non-conforming students be put on a list and that this list be submitted to recreational establishments in order for them to access ablution facilities in conformity with their gender expression. This suggestion was rejected outright as it would unduly expose students to being actively policed and place them at risk of being violated on account of their sexual orientation, gender expression and gender identity. Another suggestion was that security guards accompany these students in order to make use of the ablution facilities in conformity with the sex assigned to them at birth. This suggestion was also rejected. Such reasoning encourages an environment where people are once more policed, reduces their agency and autonomy, creates a false sense of inclusivity and transformation and instead strengthen the heteronormative institutional culture. 
In another matter regarding student accommodation, a workshop was scheduled with the House Committee facilitated by Triangle Project. The LGBTIQ-identifying student was subsequently moved out of the room. No formal charges were brought against the heterosexual identifying student. In contrast to this negative experience in residence, two gender nonconforming students have been allowed to share a double room due to them being uncomfortable sharing a room with their heterosexual-cisgender counterparts. This is quite progressive since it occurred in the absence of formal policy providing guidance on the matter.

\section{GENDER EQUITY UNIT'S APPROACH TO AWARENESS-RAISING}

Through student activism, awareness-raising initiatives are highly political. The role of the supporting staff is to provide guidance and facilitate and ensure programme implementation within the Gender Equity Unit's ideological framework that is premised on feminism, human rights and social justice. Hence, advocacy work promotes the idea of equitable transformation more so than mere social inclusion. Advocating against social exclusion does not amount to social inclusion (Levitas 2003). When advocating for full campus citizenship to be afforded to LGBTIQ students, critical questions are whether citizenship can ever be successfully universal or whether it will always be undermined by social divisions (Walby 1997, 166; McEwan 2000, 631). These are fundamental tensions that exist between acknowledging difference (plurality) and equal citizenship (universality) (McEwan 2000, 631).

In essence institutional culture allows for claims to be made about difference and similarity which creates divisions between 'us' and 'them'. In a culture of domination rooted in patriarchy, the challenge that comes with advocating for difference is distinction and possible separation that can once more lead to marginalisation (Hooks 1989,19). On the other hand, advocating for universality presupposes that we are all equal and entitled to equal treatment. In light of these two competing ideologies, how do we negotiate dignity and equality in a constitutional democracy where people have competing interests? How do we promote radical transformation for social inclusion and agency of LGBTIQ people without creating an LGBTIQ elite ('good homosexuals') that is socially included because they assimilate in opposition to the 'more deviant' LGBTIQ people? Through political awareness-raising, the Gender Equity Unit notes that formal rights 'for all' does not necessarily translate into social justice 'for all'. Hence, we proactively promote respect for difference of LGBTIQ people by engaging in public education through advocacy, advancing LGBTIQ visibility, debunking myths, promoting human rights and social justice, spreading love and ultimately stimulating critical thinking about sexuality, religion and culture.

We have successfully lobbied the university to hoist the South African 'gay' (LGBTIQ) flag bi-annually. It is hoisted in the first semester, on the $17^{\text {th }}$ of May, in celebration of 
International Day Against Homophobia and Transphobia (IDAHOT). It is also hoisted during the month of October in which we host UWC LGBTIQ Awareness Month. The aim of these two awareness-raising initiatives is to firstly raise people's awareness around matters affecting LGBTIQ people, and secondly advocating for social, structural and policy transformation.

Research done by the Gender Equity Unit amongst staff members on campus indicated a prevailing homophobic institutional culture (Hames, Beja, and Kgosimmele 2005, 177; Hames 2007, 70). However, through numerous awareness-raising initiatives focusing on staff sensitisation and education, it appears as if there may have been a slight shift in the perceptions and views of staff members. Alternatively, people could also just be creating the illusion of change because it is the politically correct thing to do. In 2014, volunteers in the LoudEnuf programme and GaylaUWC focussed on raising awareness amongst staff members by hosting a Generosity Day through which LGBTIQ identifying students distributed cup-cakes and inspirational cards reading 'Respect Difference - Spread the Love'. In turn, staff members were asked to write supportive messages or pledges in support of the struggle against a homophobic institutional culture. Staff members who partook included support-staff, lecturers, senior executive members, campus security, residential services and the HIV/Aids Unit. We obtained consent from them to take photographs with their pledges and comments for the purpose of compiling a short video to be screened to first year students and new staff members during the orientation programme at the beginning of the academic year. Although some staff members refused outright to partake in this initiative, shielding behind religion and culture, many staff members extended support. It should be noted that staff participation in this awareness-raising initiative is not concrete evidence that staff members are not homophobic or transphobic. In an environment of needing to be professional such as the modern-day corporate university, one often needs to hide one's deeply held prejudice with the aim of appearing progressive. Staff responses varied:

I am totally against xenophobia and homophobia on our campus.

Respect us enough by allowing 'me' to live my truth!!! I am proud to be gay.

Homophobia is a crime!

The Lord says that we should not hate one another.

Although they were only a few participants, they were well represented from all over campus. We now had the opportunity of locating various allies in these spaces who also became change agents in challenging homophobia and transphobia and broadened the network of support.

During awareness-raising events anonymous comments are called for to allow students to express their overall experience within the space. Here are some of the comments that have 
been obtained at the annual GaylaUWC show:

Overall, UWC is gay friendly, but there are areas where there could be improvement. I thought LGBTI was only that. I never knew that 'Questioning' was also part of it. I commend the LGBTI community for their courage to express themselves in a world where they are the minority.

Maybe it is because I am not gay, but with my friends I have never heard any stories of them being attacked or harassed due to their sexual preferences. [I have learned that] sex is biological, gender is socially constructed.

It is difficult to gauge the extent of homoprejudice in the institutional culture. One can never be sure whether the positive feedback received is indeed authentic. The aim of awareness-raising is to impart knowledge that will provide people with the opportunity to act and think differently about LGBTIQ matters. Sometimes this may lead to an increase in prejudice, lead to an unlearning of what is known, or to a more progressive understanding.

\section{CONCLUSION}

It is disheartening to realise that the ideal of quality education for all is out of reach for many LGBTIQ people who are invisibilised, traumatised and pushed to the margins. And when recognised, an incorrect assumption is made that all LGBTIQ lived experiences are the same. LGBTIQ experiences are not monolithic or homogenous (O’Malley 2013, 355). Though the data on physical violations and discrimination against LGBTIQs is limited, anecdotal evidence exist which indicates that these groups experience high levels of stigmatisation, discrimination, verbal and physical abuse, and violence (Equality Report 2012, 48). It is also clear that genderbased violence and discrimination impacts LGBTIQ identifying people disproportionately more than heterosexual and cisgender identifying people; and that 'hate crimes' remains a silent threat to their safety (National Development Plan 2030 2012, 395). Universities, being microcosms of society, are not exempted from this fact. Institutions of higher learning are significantly patriarchal. Yet, they are tasked with the responsibility of creating safe, inclusive and transformed environments for all to achieve their full potential (FAWE 1998, 6; Joyce and Ngaling 2007, 63).

I am in agreement with Pumla Gqola's position, as noted by Mary Hames, 'that universities are intimately implicated in the reproduction of systems of power and that they are not the cerebral uncontaminated spaces they are professed to be’ (Gqola 1994, 27; Hames 2010, 56). In an environment of continued silence, the perpetuation of misconceptions, a blatant disregard for social prejudice against LGBTIQ people in the education system, a culture of violation of LGBTIQ peoples' Constitutional rights to dignity and equality, prejudice becomes more and more justifiable (Van Vollenhoven and Els 2013, 281). Awareness-raising and 
advocacy is an effective tool to use in challenging homophobia and transphobia. However, there needs to be clear commitments from institutional functionaries, who hold the power, to affect direct policy transformation. The two approaches should be mutually complementary, with awareness-raising stimulating transformation from the bottom up, while progressive policy and decision-makers stimulate transformation from the top down. Without such institutional commitment, LGBTIQ students will continuously be victimised by a patriarchal system that applies patriarchal norms and values that reinforce heteronormativity, cisnormativity homophobia and transphobia. Should our institutions not take heed of the homophobia and transphobia that plague our campuses and should they not be proactive in challenging this social ill it might indicate a lack of commitment towards making 'quality education' a reality for LGBTIQ students.

\section{NOTE}

1. According to Morgan, Marais, and Wellbeloved $(2009,5)$ the term 'gender non-conforming' is defined as a person whose behaviour and expression (through particularly dress-code) does not correspond with the social and cultural norms set by society.

\section{REFERENCES}

Akoojee, S. and M. Nkomo. 2007. Access and quality in South African higher education: The twin challenges of transformation. South African Journal of Higher Education 21(3): 385-99.

Alteration of Sex Description and Sex Status Act 49 of 2003. 2003. Government Gazette Vol. 465 No. 26148 (15 March 2004).

Arndt, M. and G. de Bruin. 2006. Attitudes towards lesbians and gay men: Relations with gender, race and religion among university students. 33 PINS: 16 - 30.

Butler, A., A. Alpaslan, J. Strüumpher and G. Astbury. 2003. Gay and lesbian youth experiences of homophobia in South African Secondary Education. Journal of Gay and Lesbian Issues in Education 2: 3-28.

Butler, J. 1990. Gender trouble: Feminism and the subversion of identity. London: Routledge.

Butler, S. 2009. 'Considering 'objective' possibilities in autoethnography: A critique of Heewon Chang's autoethnography as method'. The Weekly Qualitative Report 2(51): 295-329.

Cavanagh, S. L. 2010. Queering bathrooms: Gender, sexuality and hygienic imagination. Canada: University of Toronto Press.

Chang, H. 2008. Autoethnography as method. California: Left Coast Press.

Chmielewski, J. F. and M.R. Yost. 2013. Psychosocial influences on bisexual women's body image: Negotiating gender and sexuality’. Psychology of Women Quarterly 37: 242-250.

Constitution of the Republic of South Africa Act 108 of 1996. 1996. Government Gazette Vol. 378 No. 17678 (18 December 1996).

Davids, N. 2012. Varsity in 'gaybashing' row. The Times 31 October 2012. http:www.timeslive.co.za/ news/south-africa/2012-10-31-varsity-in-gaybashing-row/

De Vos, P. 2012. On blaming the victim. http://constitutionallyspeaking.co.za/category/sexualorientation/page/2/

Ellis, C. J. and A. P. Bochner. 2000. Analysing analytic autoethnography. Journal of Contemporary Ethnography 35(4): 419-428. 
FAWE. 1998. Creating an enabling and empowering environment for women in tertiary education: A handbook for African universities. Nairobi: FAWE.

Foucault, M. 1988. Technologies of the self: A seminar with Michel Foucault. Tavistock, Andover, Hants.

Garvey, J. C. and S. R. Rankin. 2015. The influence of campus experiences on the level of outness among trans-spectrum and queer-spectrum students. Journal of Homosexuality 62(3): 374-393.

Gershenson, O. 2010. The restroom revolution: Unisex toilets and campus politics. http://works. bepress.com/olga-gershenson/3/

Gevisser, M. and E. Cameron. 1995. Defiant desire. Braamfontein: Ravan Press.

Gherhardi, S. 1995. Gender, symbolism and organisational cultures. London: Thousand Oakes; New Delhi: Sage.

Glam, L. 2014. The cost of coming out. The Big Issue 25 May 2014.

Government Gazette. 2014. Draft social inclusion policy framework for public post-school education and training institutions. (General Notice 68 of 2014).

Gqola, P. D. 1994. Language and power: A black woman's journey through three South African universities. In Hear our voices: Race, gender and the status of black South African women in the academy, ed. R. Mabokela and Z. Magubane, 25-40. Pretoria: University of South Africa Press; Leiden: Koninklijke Brill NV.

Grant, B. M. 2007. The mourning after: Academic development in time of doubt. International Journal for Academic Development: 35-43.

Hames, M., N. Beja and T. Kgosimmele. 2005. The impact of sexual harassment policies in South African universities: The University of the Western Cape. In Killing a virus with stones? ed. J. Bennett, 151-195. African Gender Institute.

Hames, M. 2007. Sexual identity and transformation at a South African university. Social Dynamics 33(1): 52-77.

Hames. M. 2010. Se(x)ation, sensation or research? Interrogating the research gaze. BUWA! 1(1): 53 55.

Hanson, J. 2013. Educational development as researchers: The contribution of insider research to enhancing understanding of role, identity and practice. Innovation in Education and Teaching International 50(4): 388-398.

Herek, G. M. and K. T. Berrill. 1992. Hate crimes: Confronting violence against lesbians and gay men. Newbury Park, California: Sage.

Hockey, J. 1993. Research methods: Researching peers and familiar settings. Research Papers in Education: 35-43.

Hooks, B. 1989. Talking back; rethinking feminist*thinking black. Boston: South End Press.

Jeffreys, S. 2014. The politics of the toilet: A feminist response to the campaign to 'degender' a woman's space. Women's Studies International Forum 45: 42-51.

Joyce, B. Mbongo Endeley and Margaret Nchang Ngaling. 2007. Challenging gender inequality in higher education: Attitudes and perceptions of teaching staff and administrators at the University of Buea, Cameroon. 9 Feminist Africa: Rethinking Universities II: 63-84.

Kitzinger, J. and C. Kitzinger. 2012. The 'window of opportunity' for death after severe brain injury: Family experiences. Sociology of Health \& Illness. doi:10.1111/1467-9566.12020

Levitas, R. 2003. The idea of social inclusion. A paper presented a t the Social Inclusion Research Conference. http://www.ccsd.ca/events/inclusion/papers/rlevitas.html

Lewis, D. K. 1973. Anthropology and colonialism. Current Anthropology 14: 581-602.

Lopez, G. and N. Chimz. 1993. Classroom concerns of gay and lesbian students: The invisible minority. College Teaching 41(3): 97-103. 
Lorber, J. 2012. Why do bathrooms matter? Contemporary Sociology 41(5): 598-601.

Lovaas, K. E., L. Baroudi and S. M. Collins. 2002. Transcending heteronormativity in the classroom: Using queer and critical pedagogies to alleviate trans-anxieties. In Addressing homophobia and heterosexism on college campuses, ed. E. P. Cramer, 177-189. New York: Harrington Park Press.

Mail \& Guardian online. 2012. University of WC faces rights row after transgender student beaten, 31 October 2012. http://www.mg.co.za/article/2012-10-13-rights-row-at-western-cape-varsity

McEwan, C. 2000. Engendering citizenship: Gendered spaces of democracy in South Africa1 9(5) Political Geography 19(5): 627-651.

Morgan, R., C. Marais and J. R. Wellbeloved. 2009. Trans: Transgender life stories from South Africa. Auckland Park: Fanele.

Msibi, T. 2013. Queering transformation in higher education. Perspectives in education 31(2): 65-73.

Muller, U. 2000. Gender equality programmes in German institutions of higher education the north Rhine-Westphalia case. Higher Education in Europe 25: 155-161.

National Development Plan for South Africa 2030. 2012. Department of the Presidency. Sherino Printers.

O’Malley, M. P. 2013. Creating inclusive schools for LGBTIQ youth, staff and families: Equitable education leadership and research practice. In Handbook of research on educational leadership for equity and diversity, ed. L. Tillman and J. J. Scheurich, 355-379. New York, NY: Routledge.

Promotion of Equality and Prevention of Unfair Discrimination Act 4 of 2000. 2000. Government Gazette Vol. 451 No. 24249 (15 January 2003).

Rankin, S. 2003. Campus climate for gay, lesbian, bisexual and transgender people: A national perspective. New York: National Gay \& Lesbian Task Force.

Rankin, S., G. Weber, W. J. Blumenfeld and M. S. Frazer. 2010. 2010 State of Higher Education for LGBT People. Charlotte, NC: Campus Pride.

Reid, G. and T. Dirsuweit. 2002. Understanding systemic violence: Homophobic attacks in Johannesburg and its surrounds. Urban Forum 13(3): 99-126.

Renn, K. A. 2000. Including all voices in the classroom: Teaching lesbian, gay and bisexual students. College Teaching 48: 129-135.

Shackleton, L. 2007. Lost in liberalism: A case study of the disappearance of the gender agenda at a South African university. Feminist Africa: Rethinking Universities II 9: 23-41.

South African Human Rights Commission. 2012. Equality Report: Human Rights Commission of South Africa.

University of the Western Cape mission statement. 2012. http://www.uwc.ac.za/Faculties/ NS/SANBI/Pages/Mission-Statement.aspx (accessed 21 April 2016).

Valentine, G. 1993. (Hetero)sexing space: Lesbian perceptions and experiences of everyday spaces. 11Society and Spaces: 395-413.

Van Vollenhoven, W. and C. J. Els. 2013. The human rights paradox of lesbian, gay, bisexual and transgender students in South African education. De Jure 46(1): 263-284.

Walby, S. 1997. Gender transformation. London: Routledge.

White Paper for Post-school Education and Training. 2014. Government Gazette Vol. 583 No. 37229 (15 January 2014).

White Paper 3 on transformation in Higher Education. 1997. Government Gazette Vol. 386 No. 18207 (15 August 1997).

Wilkinson, S. and C. Kitzinger. 2013. Representing our own experiences: Issues in 'insider' research. Psychology Women Quarterly 37(2): 251-255. 